\title{
Community-Acquired Pneumonia 2000-2015: What is New?
}

\author{
Catia Cillóniz, PhD and Antoni Torres, MD
}

Department of Pneumology, Institut Clinic del Tórax, Hospital Clinic of Barcelona, Institut d'Investigacions Biomèdiques August Pi i Sunyer IDIBAPS, University of Barcelona, Ciber de Enfermedades Respiratorias (Ciberes), Barcelona, Spain

\section{ABSTRACT}

Despite the development of new diagnostic tests, new antimicrobial agents, and the implementation of international guidelines in recent decades, community-acquired pneumonia still has high morbidity and mortality worldwide and is associated with moderate health costs. Streptococcus pneumoniae is still the most frequent pathogen related to microbial aetiology of community-acquired pneumonia, although almost $50 \%$ of cases of pneumonia still have no microbiological diagnosis. However, the development of molecular techniques such as real-time polymerase chain reaction in the past five years has revealed respiratory viruses to be major causative agents in community-acquired pneumonia. With the explosion of information from the many studies focusing on community-acquired pneumonia epidemiology, microbial aetiology and management in the last 15 years, the introduction of predictive tools, and advances in the pathophysiology of the disease, management of community-acquired pneumonia has also improved over this time due to the implementation of international guidelines proposed by different scientific associations. This review focuses on the new data in the management of community-acquired pneumonia. (BRN Rev. 2016;2:253-73)

Corresponding author: Antoni Torres, atorres@clinic.ub.es

Key words: Community acquired pneumonia. Management. Pneumonia. 


\section{INTRODUCTION}

Despite the development of new diagnostic tests, new antimicrobial agents, and the implementation of international guidelines in recent decades, community-acquired pneumonia (CAP) still has high morbidity and mortality worldwide and is associated with moderate health costs ${ }^{1}$.

There is consistent evidence that the incidence of CAP has risen in recent decades and the hospitalization rate has increased. However, there is no concrete explanation for this phenomenon ${ }^{2}$. It is true that mortality related to CAP has declined over time in the general population ${ }^{3}$. However, in patients with severe CAP, mortality rates remain as high as 35\% in cases requiring admission to an intensive care unit (ICU) .

Streptococcus pneumoniae (pneumococcus) remains the most frequent pathogen in CAP in all settings (outpatients, patients requiring hospitalization, and patients requiring ICU treatment), in all age groups, and regardless of comorbidity ${ }^{5}$. The improvement of molecular diagnostic techniques in the last years has demonstrated the increasing prevalence of respiratory viruses in $\mathrm{CAP}^{6}$. The Middle East respiratory syndrome coronavirus (MERS-CoV) outbreak, the severe acute respiratory syndrome coronavirus (SARS-CoV) epidemic, and the $2009 \mathrm{H} 1 \mathrm{~N} 1$ influenza pandemic are some examples of new viral pathogens involved in pneumonia?.

Another important difficulty related to the management of CAP patients is the considerable problem with the emergence of antimicrobial resistance of common pathogens in
CAP, especially multidrug-resistant pneumococcal clones and gram-negative bacilli.

Moreover, we know that the increased use of antibiotics generates resistance in microorganisms through adaptation to antibiotic pressure. Between 2000 and 2010, global antibiotic use increased by $36 \%$ from approximately 50 to 70 billion standard units, based on data from 71 countries, including most countries with large populations ${ }^{8}$ (Fig. 1).

This review focuses on the data published from 2000 to 2015 on the more important aspects of CAP.

\section{EPIDEMIOLOGY OF COMMUNITY-ACQUIRED PNEUMONIA}

World Health Organization (WHO) 2012 statistics indicate that lower respiratory tract infections (LRTI) are the fourth cause of death globally and the number one cause of death in low-income countries 9 . In the USA, pneumonia was reported as the ninth most common cause of death in $2010^{10}$. In 2013, The Global Burden of Disease Study reported that LRTI are the second cause of death; this report was based on data from 188 countries around the world ${ }^{11}$. In Europe, mortality rates for CAP vary widely from country to country, ranging from $<1$ to $48 \% 1$.

In a comprehensive literature review, Torres et al. $^{12}$ found the overall annual incidence of CAP in Europe to be between 1.07 and 1.2 per 1000 person-years and 1.54 and 1.7 per 1000 population. In the same review, the authors found that the incidence of CAP 


\section{TREATMENT TRENDS}

The first comprehensive, global report on antibiotic use shows that the drugs are increasingly popular in low- and middle-income countries.

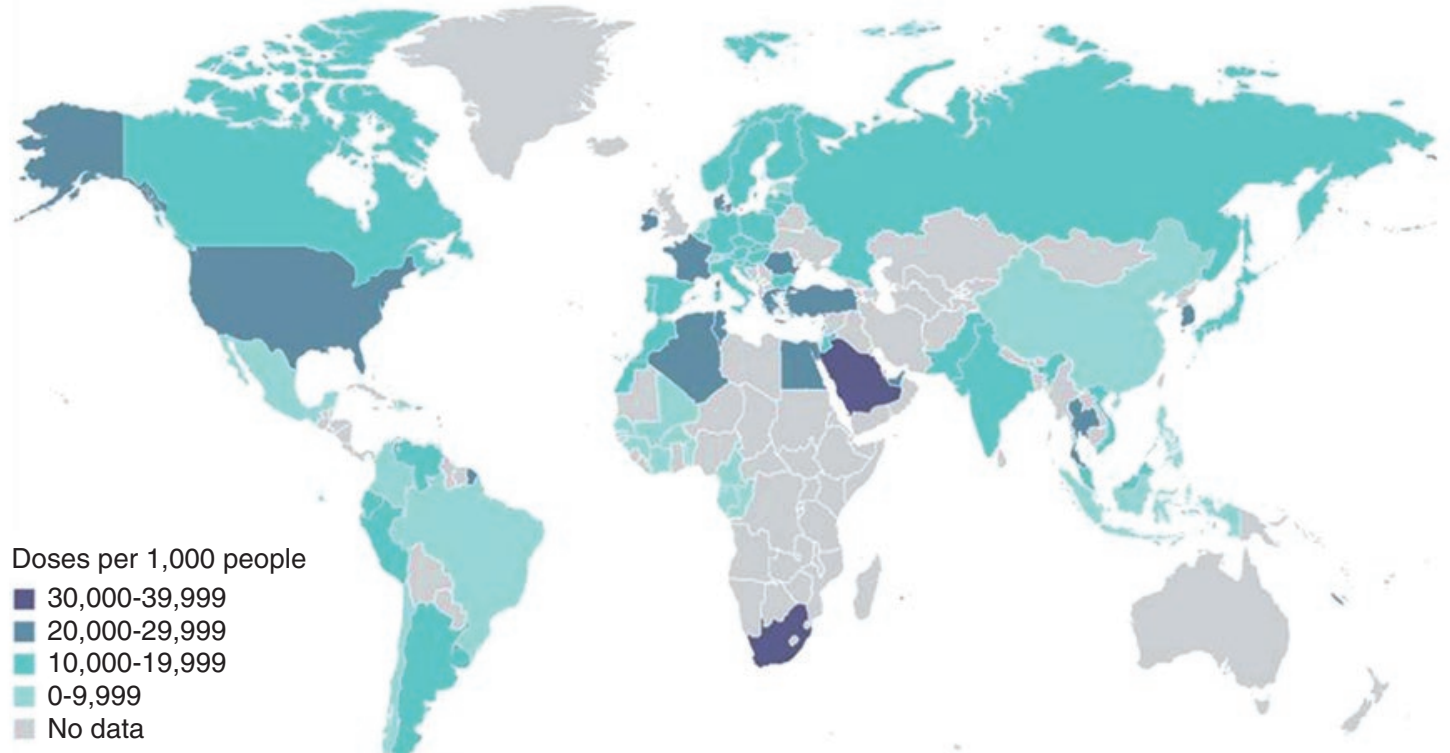

Figure 1. Global trend in antibiotic consumption (reproduced with permission from Reardon S. Dramatic rise seen in antibiotic use. Nature. 2015 Sep).

increased with age to 14 per 1000 person-years in adults aged $\geq 65$ years and the incidence of CAP was significantly higher in men than in women $^{12}$ (Fig. 2).

The Etiology of Pneumonia in the Community (EPIC) study reported by Jain et al. ${ }^{6}$ found an increased incidence of pneumonia with increasing age; the annual incidence of pneumonia in the US was 24.8 cases per 10,000 adults, with the highest rates among adults $65-79$ years of age ( 63.0 cases per 10,000 adults) and those 80 years of age or older (164.3 cases per 10,000 adults).

The economic cost related to CAP remains high. A recently published Dutch study that included 195,372 CAP cases reported that the median costs of CAP case were dependent on age and type of care, with costs ranging from $€ 344$ (€482) per episode for 0-9 year olds treated as outpatients, to $€ 10,284$ ( $€ 16,374)$ per episode for 50-64 year olds admitted to the $\mathrm{ICU}^{13}$. Another major study that provides an overview of the importance of comorbidity conditions in the economic cost of pneumonia (Fig. 3) is the recently published study by Weycker et al. ${ }^{14}$ on the rates and cost of invasive pneumococcal disease and pneumonia in persons with underlying medical conditions.

Despite the implementation of important measures in recent decades, such as widespread 


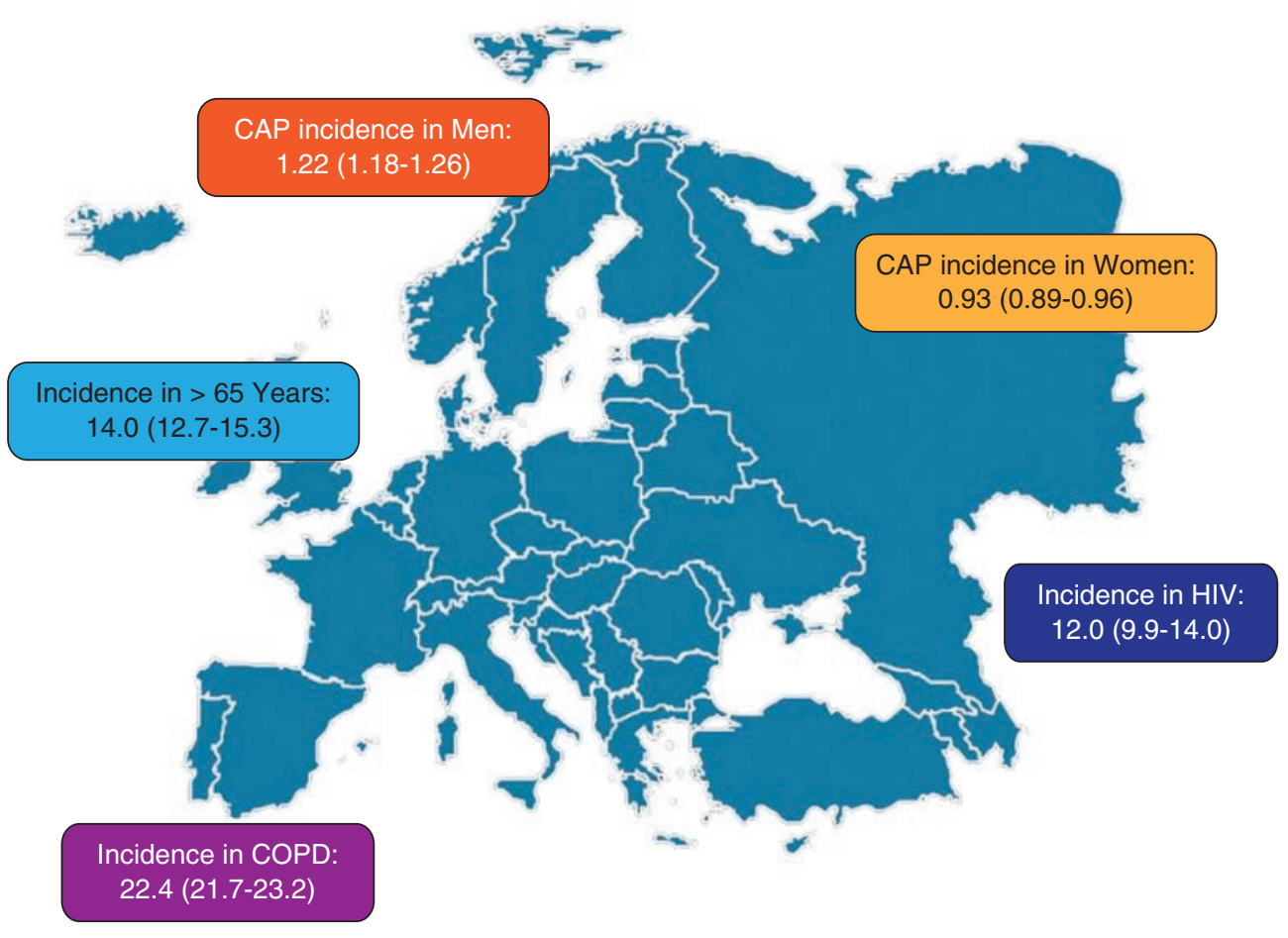

Figure 2. Overall CAP incidence* in Europe. Literature review in $>15$ y.o. patients, 60 Studies (Reproduced with permission from Torres $A$ et al. Thorax: 2013;68:1057-65).

*All incidences reported as per 1000 Person Years.

CAP: community-acquired pneumonia.

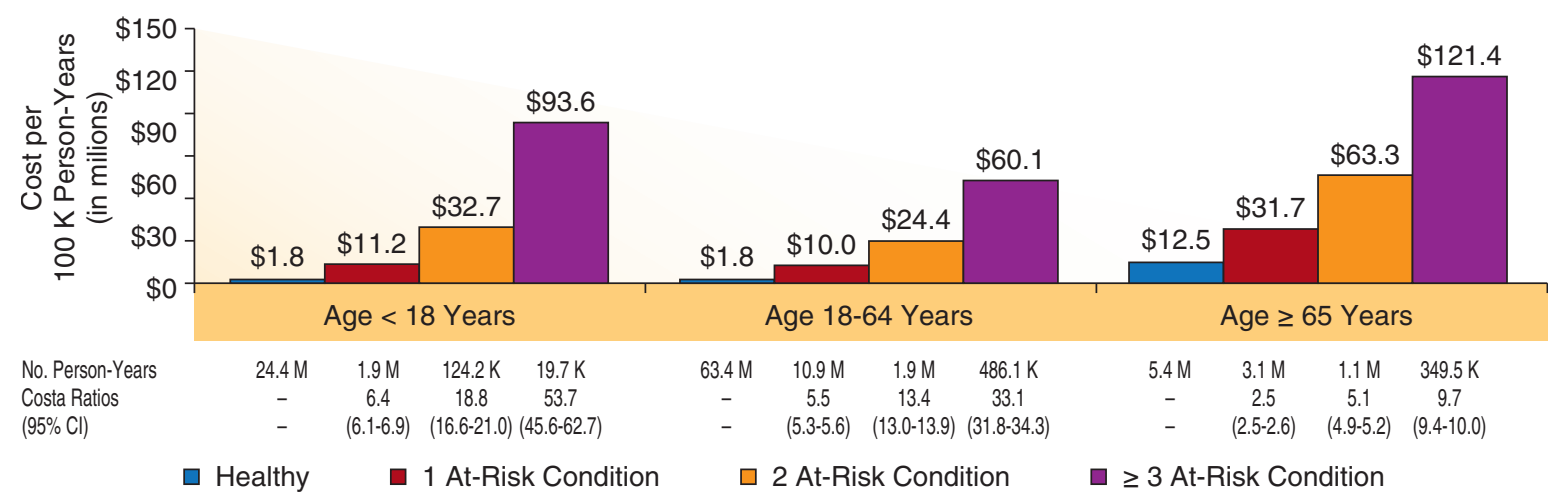

Weycker D, Farkouh RA, Strutton DR, Edelsberg J, Shea KM, Pelton SI. Rates and costs of invasive pneumococcal disease and pneumonia in persons with underlying medical conditions. BMC Health Serv Res. 2016 May 13;16:182. doi: 10.1186/s12913-016-1432-4.

Figure 3. Annual cost of all-cause prneumonia per 100,000 persons with risk conditions, by number of conditions, versus their healthty counterparts (reproduced with permission from BMC Journal).

* Risk condition: presence of medical condition. 
use of pneumococcal conjugate vaccine and influenza vaccination, implementation of international guidelines that help in the use of appropriate antibiotic treatment and reducing length of hospital stay, the rate and cost for persons with risk conditions such as asthma and diabetes have increased in recent years ${ }^{14}$.

\section{RISK FACTORS}

In the past 15 years, several studies have reported specific risk factors for $\mathrm{CAP}^{15,16}$.

\section{Age}

Pneumonia can occur at any age, but its incidence increases significantly with advanced age. The EPIC study reported by Jain et al. ${ }^{6}$ found an increased incidence of pneumonia with increasing age; the annual incidence of pneumonia was 24.8 cases per 10,000 adults, with the highest rates among adults aged between 65 and 79 years (63.0 cases per 10,000 adults) and those aged 80 years or older (164.3 cases per 10,000 adults). Viral pneumonia is most frequent in middle-aged adults ${ }^{17}$. However, the incidence is variable in immunocompetent adults and increases with epidemics and ageing ${ }^{18}$.

\section{Male sex}

A recently published article by Li et al. ${ }^{19}$ suggested that being male is an increased risk for increase hospital mortality in patients admitted to the ICU with pneumonia.

\section{Lifestyle factors and risk of community-acquired pneumonia}

Several case-control studies have demonstrated the association between lifestyle factors and the risk of $\mathrm{CAP}^{15}$.

- Exposure to cigarette smoke was associated with an increased risk of CAP. Smoking is associated with colonization by pathogenic bacteria and an increased risk of lung infections, especially in the case of $S$. pneumoniae ${ }^{20}$.

- Higher consumption of alcohol ( $\geq 80 \mathrm{~g} / \mathrm{l})$ is a risk factor for CAP. Samokhvalo et al. ${ }^{21}$ performed a meta-analysis that showed that the consumption of 24,60 , and $120 \mathrm{~g}$ of pure alcohol daily resulted in a relative risk for CAP incidents of 1.12 (95\% CI: 1.02-1.23), 1.33 (95\% CI: 1.06-1.67), and 1.76 (95\% CI: 1.13-2.77), respectively, relative to non-drinkers.

- Being underweight is associated with increased risk of CAP, so it is reported that obese patients with pneumonia have lower mortality compared to normal weight patients ${ }^{12}$.

- Living conditions: living in a household of more than 10 people, regular contact with children, higher levels of education, and good dental hygiene were associated with reduced risk of $\mathrm{CAP}^{12,16}$.

\section{Specific comorbidities and risk of community-acquired pneumonia}

- Patients with chronic respiratory diseases (including chronic obstructive pulmonary 
disease [COPD], bronchitis and asthma) had a two- to fourfould to fourfold increase in the risk of CAP. In the case of COPD, a study by Restrepo et al. ${ }^{22}$ analysed 744 patients with CAP and reported that COPD patients with CAP had a higher PSI score (105 \pm 32 versus $87 \pm 34$ ) compared with patients without COPD; these patients were also admitted more frequently to the ICU (25 versus $18 \%$ ). COPD patients with CAP exhibited higher 30-day and 90-day mortality than patients without COPD. Some studies suggested that the use of inhaled corticosteroid usually administrated in COPD and asthma patients may increase the risk of $\mathrm{CAP}^{23,24}$. However, despite the risk of CAP observed, many studies reported that prior use of inhaled corticosteroids reduced CAP mortality in COPD patients ${ }^{25}$.

- Chronic cardiovascular disease increased the risk of CAP up to threefold ${ }^{15}$.

- Cerebrovascular disease/stroke and dementia approximately doubled the risk of $\mathrm{CAP}^{26}$.

- Diabetes mellitus was associated with a moderate increase in the risk of $\mathrm{CAP}^{27}$.

- Chronic liver or renal disease increased the risk of CAP approximately twofold ${ }^{15}$.

- Hospitalization in the previous five years was associated with an increased risk of $\mathrm{CAP}^{16}$.

- Immunosuppression: human-immunodeficiency virus (HIV) infection, asplenia ${ }^{28}$.

\section{Genetic Factors}

New studies have revealed that host genetic susceptibility is a risk factor for CAP. Some studies suggest that specific mutations or polymorphisms play an important role in the variable immune response to CAP. The innate immune system is crucial to host defences against pathogenic microorganism. Toll-like receptors (TLR) are proteins that recognize bacterial pathogens.

- Toll-like receptor 4 (TLR4) A299G polymorphism. The results of a recently published meta-analysis ${ }^{29}$ suggest that susceptibility to pneumonia is associated with TLR4 A299G polymorphism.

- TLR6 polymorphism is associated with increased risk of Legionnaires' disease $^{30}$.

\section{Other risk factors}

The use of proton pump inhibitors also has been reported as additional risk factor for $\mathrm{CAP}^{31}$. A recent systematic review and meta-analysis of the risk of CAP with outpatient proton pump inhibitor therapy found the risk of CAP increased 1.5-fold in outpatients using proton pump inhibitor therapy ${ }^{32}$.

\section{CAUSATIVE PATHOGENS}

Several studies on the microbial aetiology of CAP have been published in the past 15 years ${ }^{6,33}$. Some of them showed that microbial causes of CAP differ according to the severity of disease at clinical presentation ${ }^{34}$ (Table 1).

Streptococcus pneumoniae (pneumococcus) remains the most frequent pathogen in CAP. However, its incidence is decreasingly reported due to several factors including the 
TABLE 1. Microbial aetiology of community-acquired pneumonia

\begin{tabular}{|c|c|c|c|c|c|}
\hline Outpatients & $\begin{array}{c}\text { Frequency } \\
(\%)\end{array}$ & Hospitalized (non-ICU) & $\begin{array}{c}\text { Frequency } \\
(\%)\end{array}$ & ICU patients & $\begin{array}{c}\text { Frequency } \\
(\%)\end{array}$ \\
\hline Streptococcus pneumoniae & 35 & Streptococcus pneumoniae & 43 & Streptococcus pneumoniae & 42 \\
\hline Atypical bacteria & 36 & Atypical bacteria & 16 & Atypical bacteria & 14 \\
\hline Legionella pneumophila & 6 & Legionella pneumophila & 8 & Legionella pneumophila & 8 \\
\hline Mycoplasma pneumoniae & 17 & Mycoplasma pneumoniae & 3 & Mycoplasma pneumoniae & 2 \\
\hline Chlamydophila pneumoniae & 6 & Chlamydophila pneumoniae & 3 & Chlamydophila pneumoniae & 3 \\
\hline Coxiella burnetii & 7 & Coxiella burnetii & 2 & Coxiella burnetii & 1 \\
\hline Respiratory viruses & 9 & Respiratory viruses & 12 & Respiratory viruses & 4 \\
\hline Haemophilus influenzae & 5 & Haemophilus influenzae & 5 & Haemophilus influenzae & 3 \\
\hline Polymicrobial aetiology & 9 & Polymicrobial aetiology & 13 & Polymicrobial aetiology & 22 \\
\hline Pseudomonas aeruginosa* & 1 & Pseudomonas aeruginosa* & 4 & Pseudomonas aeruginosa* & 5 \\
\hline GNEB & 1 & GNEB & 2 & GNEB & 1 \\
\hline Staphylococcus aureus & 1 & Staphylococcus aureus & 2 & Staphylococcus aureus & 2 \\
\hline
\end{tabular}

*The frequency is determined by the presence or absence of specific risk factors.

GNEB: gram-negative enteric bacilli.

(Reproduced with permission from World Health Organization (WHO). The top 10 causes of death. 2016\%).

introduction of polysaccharide vaccine PCV7 and PCV13 and the decreased rate of smoking in countries such as the USA ${ }^{35}$. An estimated prevalence of $19.3-27.9 \%$ was reported for S. pneumoniae in Europe ${ }^{36}$. Furthermore, pneumococcus was observed less frequently in CAP cases treated in the community than in cases treated in the hospital or ICU. Intracellular pathogens (Mycoplasma pneumoniae, Legionella pneumoniae, Chlamydophila pneumonia, Chlamydophila psittaci and Coxiella burnetii), together with pneumococcus, are the most frequently reported pathogens causing CAP in both outpatients and hospitalized patients ${ }^{33}$. A study by Arnold et al. ${ }^{37}$ reported a $20 \%$ incidence of intracellular pathogens in CAP patients. Intracellular pathogens sometimes appear to cause more severe disease with respiratory failure and multisystem dysfunction associated with fatal outcomes. These microorganisms may cause severe CAP in approximately $1-7 \%$ of cases $^{33}$.

Respiratory viruses are also a common cause of CAP and account for $7-36 \%$ of cases with defined microbial aetiology $y^{6,38}$. The incidence of respiratory viruses varies with seasonality, geographic location, and age group. A good example of this is the recently published study by Jain et al. ${ }^{6}$ on CAP in hospitalized adult patients, where the three principal pathogens reported in this study were rhinovirus $(9 \%)$, influenza virus $(6 \%)$, and S. pneumoniae $(5 \%)$. It is known that seasonal influenza virus and respiratory syncytial virus cause pneumonia in very young and very old patients ${ }^{39}$. However, pandemic viruses affect mostly children and younger adults ${ }^{40}$. 
Newer pathogens have been documented including human metapneumovirus (hMPV) in $2001^{41}$, and coronavirus responsible for SARS$\mathrm{CoV}$ in $2002^{42}$. Human bocavirus discovered in $2005^{43}$ and, more recently, MERS-CoV described in $2012^{44}$, community-acquired methicillin-resistant Staphylococcus aureus (CA-MRSA) ${ }^{45}$, and H1N1 pandemic influenza virus in 2009 have also become CAP pathogens relatively recently.

Antibiotic-resistant pathogens are a worldwide concern. Approximately $6 \%$ of CAP cases are caused by multidrug-resistant (MDR) pathogens. (S. aureus and P. aeruginosa were most frequently isolated) ${ }^{46}$. In a European study of pathogens isolated from hospitalized patients with CAP, MDR pathogens were the cause of CAP in $3.3-7.6 \%$ of patients in whom a pathogen was identified, with methicillinresistant $S$. aureus being the most common MDR pathogen ${ }^{47}$. The study by Prina et al. ${ }^{46}$ that analysed 1,519 patients with CAP who presented aetiological diagnosis, found that PES (Pseudomonas aeruginosa, Enterobacteriaceae extended spectrum b-lactamase-positive, and methicillin-resistant Staphylococcus aureus) pathogen was identified in $6 \%$ of the CAP cases. The study also found that PES pathogens are associated with increased risk of 30-day mortality (OR: 2.51; 95\% CI: 1.20-5.25; $\mathrm{p}=0.015$ ). This study proposed a score to assess the risk of pneumonia due to PES pathogens (Table 2).

Furthermore, S. pneumoniae, the most common cause of CAP, has increased its resistance to several antibiotics (cephalosporins, macrolides and fluoroquinolones) worldwide in the last two decades ${ }^{48}$. Currently, 20-30\% of pneumococcus disease cases worldwide are MDR (resistant to more than three classes of antibiotics) (Fig. 4).
TABLE 2. Score to assess the risk of pneumonia due to PES pathogens.

\begin{tabular}{|l|c|}
\hline Score to PES patogen & Points \\
\hline Age $>65$ y & 1 point \\
\hline Male & 2 points \\
\hline Previous antibiotic use & 2 points \\
\hline Chronic respiratory disorder & 2 points \\
\hline Chronic renal desease & 2 points \\
\hline At Emergency & \\
\hline Consciousness impairment or aspiration evidence & 2 points \\
\hline Fever or shivers & -1 point \\
\hline
\end{tabular}

PES: denotes Pseudomonas aeruginosa, enterobacteriaceae Extended Spectrum Beta Lactamase (ESBL+), Staphylococcus aureus methyciline resistant (MRSA) ${ }^{56}$.

However, mortality rates related to antibiotic-resistant S. pneumoniae have not increased due to interventions such as conjugated pneumococcal vaccine, which covers the serotypes that are most likely to express resistance ${ }^{49}$. A recent Spanish study ${ }^{50}$ compared clinical outcomes in hospitalized patients with and without macrolide-resistant pneumococcus and reported no evidence suggesting that patients hospitalized for macrolide-resistant S. pneumoniae pneumonia were more severely ill on presentation or had worse clinical outcomes if they were treated with guideline-compliant versus noncompliant regimens.

Community acquired MRSA has become an important CAP pathogen. Community and hospital MRSA share a mecA gene that confers universal methicillin and $\beta$-lactam resistance, but CA-MRSA presents broader antibiotic susceptibility than hospital MRSA. CA-MRSA carries the gene for the Panton-Valentine leukocidin (PVL) toxin, which causes leukocyte destruction and tissue necrosis ${ }^{51}$. Pseudomonas aeruginosa is not a frequent pathogen in $\mathrm{CAP}^{33}$. However, several studies reported that 
Year of Introduced Antibiotic

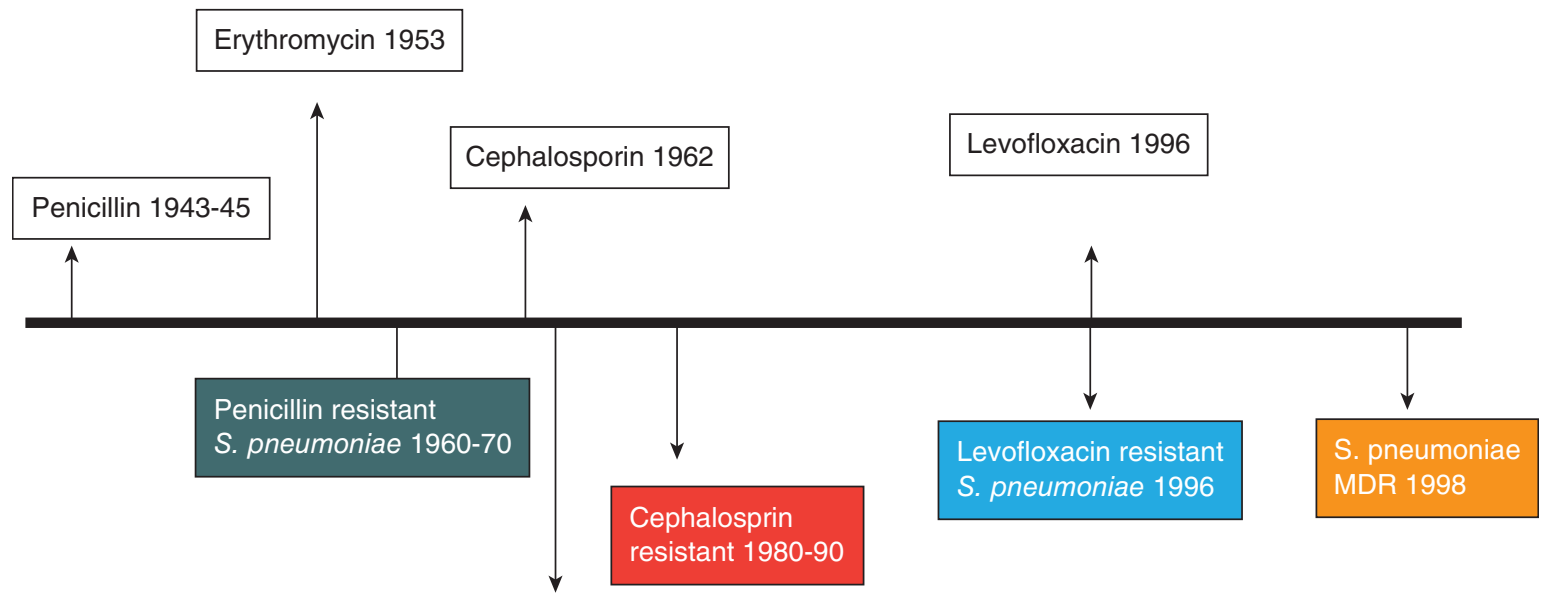

Erythromycin resistant

S. pneumoniae 1968

Year of reported resistance

FiguRE 4. Timeline of antibiotic resistance of Streptococcus pneumoniae. MDR: multi-drug resistant.

in patients with severe CAP requiring ICU admission, $P$. aeruginosa was the cause in 1.8$8.3 \%$, with a case/fatality rate of $50-100 \%{ }^{5,52}$. Prevalence of MDR P. aeruginosa is not well known in CAP. A study by Cilloniz et al. ${ }^{53}$ reported $1 \%$ of cases were caused by MDR $P$. aeruginosa. They identified the use of prior antibiotic treatment as the only risk factors associated with CAP caused by MDR P. aeruginosa.

More recently, the emergence of macrolide-resistant M. pneumoniae strains ${ }^{54}$, principally in Asian countries ${ }^{55}$, in some European countries $^{56}$, and in the US ${ }^{57}$ is becoming a global problem. However, the clinical significance of macrolide resistance of $M$. pneumoniae in CAP outcomes is still unknown.

\section{RISK FACTORS ASSOCIATED WITH SPECIFIC PATHOGENS IN COMMUNITY-ACQUIRED PNEUMONIA}

Several studies have identified specific risk factors for a number of pathogens in CAP cases (Table 3).

In the case of S. pneumoniae, the most frequent pathogen in CAP cases, one study recently described the risk factors for pneumonia due to fluoroquinolone-resistant S. pneumoniae as previous use of fluoroquinolones, current residence in a nursing home, nosocomial acquisition of pneumococcal infection, penicillin resistance, and $\mathrm{COPD}^{58}$. In the US, the SENTRY study reported that the rate of 
TABLE 3. Risk factors associated with specific pathogens in community-acquired pneumonia

\begin{tabular}{|l|l|l|l}
\hline Microorganism & Risk factor \\
\hline $\begin{array}{l}\text { Streptococcus pneumoniae } \\
\begin{array}{l}\text { S. pneumoniae resistant to ß-lactam, } \\
\text { macrolides and fluoroquinolones }\end{array}\end{array}$ & $\begin{array}{c}\text { Age }<2 \text { years or } \geq 65 \text { years, receipt of } \beta \text {-lactam treatment within the previous } 3 \text { months, exposure } \\
\text { to a child who attends a day care centre, alcoholism, medical comorbidity, and immunosuppression. }\end{array}$ \\
\hline $\begin{array}{l}\text { Staphylococcus aureus } \\
\text { Community-acquired methicillin-resistant } \\
\text { S. aureus (CA-MRSA) }\end{array}$ & $\begin{array}{l}\text { Advanced age, underlying lung disease, and previous antibiotic use. } \\
\text { Previous viral upper respiratory infection, tobacco use, recent hospitalization, chronic pulmonary } \\
\text { disease. }\end{array}$ \\
\hline $\begin{array}{l}\text { Haemophilus influenzae } \\
\text { Chronic obstructive pulmonary disease treated with antibiotics or oral steroids within the previous } \\
3 \text { months. }\end{array}$ \\
\hline Pseudomonas aeruginosa & $\begin{array}{c}\text { Pulmonary comorbidity (bronchiectasis, use of systemic steroids, chronic obstructive pulmonary } \\
\text { disease especially in patients with inhaled corticosteroids) is the major risk factor. }\end{array}$ \\
\hline Legionella pneumophila & $\begin{array}{l}\text { Recent repair of domestic plumbing, use } \\
\text { of hot tubs and whirlpool spas, renal and/or hepatic failure, diabetes, and malignancy. }\end{array}$ \\
\hline
\end{tabular}

fluoroquinolone resistance in 2011 was 1.2\% $\%^{59}$, whereas, in 2012, a study involving European countries reported a rate of $5.2 \%{ }^{60}$. In Asia, in a period between 2008 and 2009, the rate reported was $2.4 \%$ of fluoroquinolone resistance strains $^{61}$.

Risk factors for $S$. aureus include advanced age, underlying lung disease, and previous antibiotic use, whereas the two reported risk factors for methicillin-resistant $S$. aureus were prior hospitalization in the previous 90 days and requiring admission to the $\mathrm{ICU}^{47}$. Risk factors for CA-MRSA include a history of viral upper respiratory infection, smoking, recent hospitalization, and chronic pulmonary disease $^{62}$. Recognized high-risk groups for CA-MRSA carriage and infection are athletes, military personnel, detainees in jail or prison, and children in day care centres ${ }^{63}$. Since, the household is a major community-acquired reservoir for CA-MRSA, spread beyond households established this pathogen in the communities ${ }^{64}$.
For $P$. aeruginosa, pulmonary comorbidity is the major risk factor. Recently, Cilloniz et al. ${ }^{53}$, in a cohort of 2,023 patients with CAP, reported that $4 \%$ of cases were caused by $P$. aeruginosa; risk factors related to this pathogen were male sex, chronic respiratory disease, C-reactive protein $<12.35 \mathrm{mg} / \mathrm{dl}$, and PSI risk class IV-V. In the case of MDR $P$. aeruginosa $\mathrm{CAP}$, the only risk factor was prior antibiotic treatment.

\section{MICROBIOLOGICAL DIAGNOSIS}

Initial antibiotic treatment of CAP is empiric in the majority of the cases. Determining the microbial aetiology of CAP is fundamental to ensuring appropriate antibiotic therapy, which is an important factor for reducing mortality ${ }^{65}$. However, in 50\% of cases of CAP, the microbial aetiology is unknown ${ }^{66}$. International CAP guidelines ${ }^{66,67}$ recommend an optional microbiological diagnostic test in low-to-mild cases of CAP, which should be 
TABLE 4. International guidelines recommendations for microbiological diagnostic tests in community-acquired pneumonia

\begin{tabular}{|c|c|c|c|c|}
\hline Microbiological test & Outpatient & $\begin{array}{l}\text { Inpatient low } \\
\text { severity }\end{array}$ & $\begin{array}{l}\text { Inpatient non-ICU } \\
\text { moderate severity }\end{array}$ & $\begin{array}{l}\text { Inpatients ICU } \\
\text { high severity }\end{array}$ \\
\hline Sputum culture & \multirow{6}{*}{ None routinely } & $x$ & $x$ & $x$ \\
\hline Pneumococcal urinary antigen test & & \multirow{5}{*}{ None routinely } & $\mathrm{x}$ & $\mathrm{x}$ \\
\hline Legionella urinary antigen test & & & $x$ & $x$ \\
\hline Blood culture & & & $x$ & $x$ \\
\hline $\begin{array}{l}\text { Invasive respiratory tract sample } \\
\text { culture }\end{array}$ & & & & $x$ \\
\hline Others & & & & $x$ \\
\hline
\end{tabular}

ICU: intensive care unit.

(Reproduced with permission from Prina et al. Lancet. 2015;386:1097-108).

selected as clinically indicated. Blood cultures, sputum staining, sputum culture, and urinary antigen testing for Legionella and pneumococcus should be carried out in patients with severe CAP.

Microbiological diagnosis of CAP continues to be based on respiratory samples or blood culture. The main problems with these conventional methods are the low yield and long turnaround time (48-72 hours) and the fact that previous antibiotic use affects microbiological results ${ }^{68}$. However, the most important application of these methods is the ability to determine antibiotic susceptibility patterns that will allow for selection of appropriate antimicrobial therapy.

The introduction of molecular diagnostic techniques (polymerase chain reaction [PCR] or multiplex PCR), which are based on DNA or RNA detection of bacteria and viruses, offers several advantages over conventional diagnosis of the microbial aetiology of CAP: they provide results in a short time, do not require viable bacteria, and antimicrobial therapy does not influence their results ${ }^{69}$.
However, they need to be validated in clinical practice. Some studies recommended the application of molecular techniques together with conventional methods in order to increase the diagnostic yield of microbiological diagnosis of $\mathrm{CAP}^{70}$.

\section{INTERNATIONAL GUIDELINES RECOMMENDATIONS FOR MICROBIOLOGICAL DIAGNOSTIC TESTS IN COMMUNITY-ACQUIRED PNEUMONIA (TABLE 4)}

In outpatients, routine microbiological test are optional. Blood culture and sputum staining and culture are recommended in hospitalized patients and in severe CAP. Also, urinary antigen test for pneumococcus and Legionella pneumophila is recommended. There are some special situations were microbiological tests should be applied:

- Outpatients with failure of antibiotic therapy: sputum culture, urinary antigen test for Legionella pneumonia and Streptococcus pneumoniae. 
- Positive urinary antigen test for pneumococcus or Legionella: sputum and blood culture for positive urinary antigen test for pneumococcus and sputum culture for positive urinary antigen test for Legionella.

- Severe obstructive lung disease: sputum culture.

- Pleural effusion: sputum and blood culture, urinary antigen test for pneumococcus and Legionella, pleural fluid culture.

- Cavitary infiltrates: sputum culture (bacteria, fungi and mycobacteria) and blood culture.

- Active alcoholism: sputum and blood culture, urinary antigen test for pneumococcus and Legionella.

- Severe CAP admitted to ICU: sputum and blood culture, urinary antigen test for pneumococcus and Legionella, tracheal aspirate or bronchoalveolar lavage culture; viral studies also are recommended in these patients.

- Epidemiological factors or specific risk factors suggesting pathogen: urinary antigen test for Legionella (Legionnaires' disease), influenza test during influenza season.

\section{Biomarkers}

Inflammatory biomarkers have been extensively investigated as a complementary prognostic tool for the management of CAP patients. They may be useful in the diagnosis, prognosis, and follow-up treatment of CAP patients, and they are also used for investigating antibiotic modifications ${ }^{71}$.

The most frequent biomarkers studied are C-reactive protein (CRP), procalcitonin (PCT), and cytokines interleukin (IL)-6 and tumour necrosis factor (TNF)- $\alpha^{72}$.

However, IL- 6 and TNF- $\alpha$ are used for research purposes and are not routinely assessed in clinical practice.

Measurement of PCT gives information about the severity of the disease and may help physicians to differentiate typical bacterial aetiology from atypical aetiology. A study by Johansson et al. ${ }^{73}$ showed that high PCT levels are related to invasive disease and pneumococcal aetiology. Higher levels of PCT are associated with bacterial pneumonia ${ }^{74}$. A recent study by de Jong et al. ${ }^{75}$ on the efficacy and safety of PCT guidance in reducing the duration of antibiotic treatment in critically ill patients showed that PCT guidance encourages reduction of treatment duration and daily defined doses in critically ill patients with a presumed bacterial infection. This reduction was associated with a significant decrease in mortality in this population.

CRP was the pioneer biomarker and was discovered in the serum of patients with pneumococcal pneumonia. Appropriate antibiotic treatment and good outcomes have been demonstrated by decreasing levels of CRP after 3-4 days ${ }^{76}$.

Several studies showed that CRP value used together with disease severity scores such as PSI or CURB65 offered predictive severity accuracy in $\mathrm{CAP}^{71,77}$. 
The study by España et al. ${ }^{78}$ on the utility of PCT and CRP in non-severe CAP patients showed that PCT with a cut-off point of $0.15 \mathrm{ng} / \mathrm{ml}$ was the best predictor for bacterial aetiology and for selecting patients eligible for outpatient care; levels of PCT and CRP positively correlate with increasing severity of CAP.

Pro-adrenomedullin (pro-ADM) showed a good correlation between levels of this biomarker and severity and short-term mortality in CAP studies. Several studies have suggested combining this biomarker with severity scores such as PSI and CURB-65 in order to improve the prediction of mortality and complications in CAP patients ${ }^{79}$.

D-dimer: a study by Shilon et al. ${ }^{80}$ found a correlation between the levels of D-dimer and PSI risk class and hospital mortality in CAP patients. This study concluded that D-dimer levels at admission may predict the severity of CAP.

\section{TREATMENT}

Following a diagnosis of pneumonia, the clinician must decide the appropriate location for care and treatment: management in the community (outpatient), hospital admission, or ICU. Patients at low risk of complications are candidates for outpatient care, thus reducing inappropriate hospitalization and consequent inherent morbidity and costs ${ }^{66,67}$. The use of severity assessment tools can facilitate decision-making and can also guide the clinician's choice of antibiotic therapy. Delays in determining the severity of the illness and where to treat the patient may have an impact on clinical outcome and hospital costs ${ }^{1}$.

\section{ASSESSMENT OF SEVERITY AND MAKING SITE-OF-CARE DECISIONS}

Scoring systems such as the Pneumonia Severity Index (PSI) and CURB-65 score predict short-term mortality and were developed specifically to make the decision to admit to hospital more objective ${ }^{81,82}$. However, these two scores are subject to certain limitations: low sensitivity and specificity for predicting the requirement for ICU admission ${ }^{83}$; the inappropriate weight given to the age variable in the PSI score, which could obscure younger patients with severe disease and vice versa (not valid in children); and neither score considers factors such as psychosocial factors, infrequent comorbidities, or patient preference regarding treatment ${ }^{84}$.

Recently, new severity score Infectious Diseases Society of America/American Thoracic Society (IDSA/ATS) 2007 criteria $^{66}$ have been developed to determine ICU admission. In 2007, IDSA/ATS proposed different major and minor criteria to identify patients with severe CAP requiring ICU admission. This is based on physiological variables; in particular, minor criteria are easy to use and show high specificity $(91.7 \%)$ for predicting ICU admission and need for intensive respiratory or vasopressor support. Even in the absence of major criteria, the presence of at least three minor criteria is associated with complications and a high 30-day mortality risk.

More recently, Liu et al. ${ }^{85}$ proposed a modified score called the expanded CURB-65, which adds three new variables to the CURB65 score (lactic dehydrogenase $>230 \mu / 1$, albumin $<3.5 \mathrm{~g} / \mathrm{dl}$, platelet count $<100 \times 10^{9} / 1$ ); 
this new score is a comparatively simpler and more effective marker in assessing the severity of hospitalized patients with CAP. The expanded CURB-65 score significantly improves identification of high-risk patients by decreasing the relative weight of age and blood pressure and eliminating the use of imaging and comorbid illnesses in the calculation.

CAP is associated with long-term mortality ${ }^{86}$. Several risk factors have been reported to be associated with long-term mortality for CAP, including age, cardiovascular disease, COPD, low serum albumin level at admission, diabetes, and dementia ${ }^{87}$. Recent studies have focused on the relationship between CAP and cardiovascular risk as it is now known that there is link with poor outcome in patients hospitalized for CAP and also with patients after discharge ${ }^{88}$. Approximately $10-30 \%$ of cardiovascular events occur in CAP patients and are related to short-term and long-term outcomes ${ }^{89}$.

\section{INTERNATIONAL GUIDELINES RECOMMENDATION FOR ANTIMICROBIAL TREATMENT OF COMMUNITY-ACQUIRED PNEUMONIA}

In general, the choice of empirical treatment is based on three main factors: CAP can be caused by many pathogens and no specific clinical presentation, laboratory data, or radiological features that distinguish each pathogen exist.

Microbiological diagnostic tests provide information hours or days after pneumonia presents. Delay in appropriate antibiotic therapy may be associated with significant mortality ${ }^{90}$.
TABLE 5. Guidelines for the management and treatment of community-acquired pneumonia

\section{BTS guidelines ${ }^{93}$}

Outpatients/low severity

- CURB65 score of 0 to 1 .

- Empirical therapy is primarily directed at $S$. pneumoniae.

- Treat with oral amoxicillin (preferred agent, dose of $500 \mathrm{mg}$, three times daily), or doxycycline, or clarithromycin for patients hypersensitive to penicillin.

Inpatients moderate severity

- CURB65 score of 2.

- Treat with oral amoxicillin plus clarithromycin.

- When oral therapy is contraindicated, the preferred parenteral choices include intravenous amoxicillin or benzylpenicillin, together with clarithromycin.

- Alternative for patients intolerant to penicillins or macrolides: doxycycline, moxifloxacin, or levofloxacin. IV recommendations include levofloxacin monotherapy, a second generation (e.g. cefuroxime), or a third-generation (e.g. cefotaxime or ceftriaxone) cephalosporin together with clarithromycin.

Inpatients high severity

- CURB65 score of 3 to 5 .

- Treat immediately after diagnosis.

- Treat with an intravenous combination of a broad-spectrum $\beta$-lactamase stable antibiotic such as co-amoxiclav, together with a macrolide, such as clarithromycin is preferred.

- In patients allergic to penicillin, a second-generation (e.g. cefuroxime) or third-generation (e.g. cefotaxime or ceftriaxone) cephalosporin can be used instead of co-amoxiclav, together with clarithromycin.

- Patients with Pseudomonas infection: ceftazidime plus gentamicin or tobramycin (dose monitored). Alternatively, ciprofloxacin or piperacillin, plus gentamicin or tobramycin (dose monitored).

A study by Menendez et al. ${ }^{91}$ showed that the failure of physicians to adhere to guidelines is an independent risk factor for treatment failure and mortality in CAP cases. Tables 5, 6 , and 7 summarize the recommendations of the British Thoracic Society, ATS/IDSA, and European Respiratory Society/European Society of Clinical Microbiology and Infectious Diseases guidelines.

\section{Adjuvant therapy}

Because systemic corticosteroids have broadspectrum anti-inflammatory activity, they are 
TABle 6. American Thoracic Society/Infectious Diseases Society of America guidelines for the management and treatment of community-acquired pneumonia

\section{ATS/IDSA guidelines ${ }^{92}$}

\section{Outpatients/low severity}

- PSI OR CURB65 score to guide outpatient treatment.

Treat previously healthy patients with low risk of drug-resistant pneumococci with a macrolide (azithromycin, clarithromycin, or erythromycin)

(strong recommendation; level I evidence) or doxycycline (weak recommendation; level III evidence).

- Treat patients with a high risk of drug-resistant pneumococci with a fluoroquinolone or $\beta$-lactam plus macrolide.

Presence of comorbidities, use of immunosuppressing drugs, use of antimicrobials within the previous 3 months, or other risks of DRSP infection:

- Treat with respiratory fluoroquinolone (moxifloxacin or levofloxacin [750 mg]) (strong recommendation; level I evidence).

- $\beta$-lactam plus a macrolide (high-dose amoxicillin [e.g. $1 \mathrm{~g}$ three times daily] or amoxicillin-clavulanate $[2 \mathrm{~g}$ twice daily] is preferred; alternatives include ceftriaxone, cefpodoxime, and cefuroxime [500 mg, twice daily]; doxycycline [level II evidence] is an alternative to the macrolide) (strong recommendation; level I evidence).

In regions with a high rate $(>25 \%)$ of infection with high-level (MIC $\geq 16 \mathrm{mg} / \mathrm{ml}$ ) macrolide-resistant Streptococcus pneumoniae:

- Consider the use of alternative agents listed above for any patient, including those without comorbidities (moderate recommendation; level III evidence).

Patients directly admitted to hospital:

- Treat with a respiratory fluoroquinolone (strong recommendation; level I evidence) or a $\beta$-lactam plus a macrolide (strong recommendation; level I evidence).

- Preferred $\beta$-lactam agents include cefotaxime, ceftriaxone, and ampicillin; ertapenem for selected patients; with doxycycline (level III evidence) as an alternative to the macrolide.

- A respiratory fluoroquinolone should be used for penicillin-allergic patients.

Patients who require ICU admission:

- Treat with $\beta$-lactam (e.g. cefotaxime, ceftriaxone, or ampicillin-sulbactam) plus either azithromycin (level II evidence) or a fluoroquinolone (level I evidence) (strong recommendation).

- Alternatively, a respiratory fluoroquinolone and aztreonam are recommended for penicillin-allergic patients.

Patients with Pseudomonas infection:

- Treat with either an antipneumococcal, antipseudomonal $\beta$-lactam (e.g. piperacillin-tazobactam, cefepime, imipenem, or meropenem) plus either ciprofloxacin or levofloxacin (750 $\mathrm{mg}$ dose is recommended), or the above $\beta$-lactam plus an aminoglycoside and azithromycin, or the above $\beta$-lactam plus an aminoglycoside and an antipneumococcal fluoroquinolone.

- For patients allergic to penicillin, the above $\beta$-lactam should be substituted with aztreonam (moderate recommendation; level III evidence).

Patients with community-acquired methicillin-resistant Staphylococcus aureus (CA-MRSA) infection:

Add vancomycin or linezolid to standard CAP therapy (moderate recommendation; level III evidence).

ATS: American Thoracic Society; CAP: community-acquired pneumonia; DRSP: drug-resistant Streptococcus pneumoniae; IDSA: Infectious Diseases Society of America.

Table 7. European Respiratory Society/European Society of Clinical Microbiology and Infectious Diseases guidelines for the management and treatment of community-acquired pneumonia

\begin{tabular}{l|l}
\hline Low severity & Moderate to high severity \\
\hline - CURB65 to guide outpatient treatment & - ICU admission: acute respiratory failure, severe sepsis or septic shock and \\
- Treatment: & radiographic extension of infiltrates/ severely decompensated comorbidities \\
- Aminopenicillin \pm macrolide & - No risk factors for $P$. aeruginosa: Non-antipseudomonal cephalosporin III + macrolide \\
- Aminopenicillin/b-lactamase inhibitor \pm macrolide & or non-antipseudomonal cephalosporin III + moxifloxacin or levofloxacin \\
- Non-antipseudomonal cephalosporin II or III + macrolide & - Risk factors for $P$. aeruginosa: Antipseudomonal cephalosporin or acylureido \\
- Cefotaxime or ceftriaxone \pm macrolide & penicillin/ß-lactamase inhibitor or carbapenem (meropenem preferred) plus cipro- \\
- Penicillin $G \pm$ macrolide & floxacin or plus macrolide + aminoglycoside (gentamicin, tobramycin or amikacin)
\end{tabular}

ICU: intensive care unit.

used as adjunctive therapy for CAP and several studies reported their association with a short time to clinical stability, an earlier switch to oral sequence therapy, shorter length of hospital stay, less treatment failure, and lower mortality in patients with severe CAP. However, some studies suggested that systemic corticosteroids in patients with influenza 
pneumonia are associated with increased mortality ${ }^{92}$. Future studies are needed in order to determine in which cases corticosteroid therapy should be recommended.

Statin therapy is used as adjunctive therapy for CAP as some studies have shown them to have anti-inflammatory and antioxidative effects and ability to reduce cardiovascular events ${ }^{93}$. Macrolides are used as adjunctive therapy for CAP because of their several immunomodulatory effects, and because they can attenuate the virulence factors of some important bacteria, such as S. pneumoniae, where they inhibit pneumolysin production; they also inhibit the quorum sensing by bacteria ${ }^{94}$.

\section{Prevention}

International guidelines ${ }^{66,67}$ recommend specific measures to prevent pneumonia. The most important of these is the use of pneumococcal vaccines (polysaccharide and conjugated) and influenza vaccines in all older adults and for younger persons with medical conditions that place them at high risk for pneumonia morbidity and mortality. Annual influenza vaccination is also recommended in healthcare workers, inpatient and outpatient settings, and long-term care facilities.

Since the risk of CAP is increased in current smokers ${ }^{12}$, the general recommendation is to offer smoking cessation in these patients.

\section{Pneumococcal vaccination}

Vaccination remains the primary strategy for the prevention of CAP, especially in an at-risk population (young children, the elderly, patients with comorbidities, and the immunocompromised). Two types of vaccine are currently available: polyvalent pneumococcal polysaccharide vaccine (PPV) and the pneumococcal conjugate vaccines (PCV). The main difference between the types of vaccine is that PPV contains amounts $(25 \mu \mathrm{g})$ of unconjugated purified capsular polysaccharides of each of the 23 pneumococcal serotypes, whereas in PCV, the capsular polysaccharides (2-4 $\mu \mathrm{g}$ depending on the antigen) are conjugated to a carrier protein to enhance immunogenicity ${ }^{95}$. Because of the limitation of PPV23 in children, a new conjugated vaccine was developed.

Several studies assessed the effectiveness of PPV23 in CAP in the elderly ${ }^{96,97}$. Because of the limitation of PPV23 in children and adults $^{98}$, a new conjugated vaccine was developed (PCV7). Despite the success of PCV7, studies have also noted an increase in the incidence of invasive pneumococcal disease (IPD) caused by non-vaccine serotypes (especially serotype 19A $)^{99}$. A new 13 -valent pneumococcal polysaccharide-protein conjugate vaccine (PCV13) was approved by the Food and Drug Administration (FDA) in February 2010 for the prevention of IPD in infants and young children, caused by the 13 serotypes in the vaccine. In March 2010, The Advisory Committee for Immunization Practices (ACIP) recommended that $\mathrm{PCV} 13$ replace $\mathrm{PCV} 7$ for the vaccination of children. In 2011, the FDA approved the use of PCV13 in adults aged 50 years and older for the prevention of pneumococcal pneumonia and IPD. On July 12 2016, the FDA approved expanding the indication of PCV13 vaccine to include adults 18 through 49 years of age ${ }^{100}$. 
A recently published randomized doubleblind, placebo-controlled study (CAPiTA) was conducted in the Netherlands, involving 84,496 adults aged 65 years and over, between 2008 and 2013, to evaluate the efficacy of PPV13 vaccine in preventing the first episode of vaccine-type strains of pneumococcal CAP, non-bacteremic and noninvasive pneumococcal CAP, and IPD. The results showed $45.5 \%$ (95.2\% CI; 21.8-62.5; p < 0.001) efficacy of PCV13 gains all vaccine type pneumococcal CAP, $45 \%$ (95.2\% CI: 14.2-65.3; $\mathrm{p}<0.001)$ efficacy against vaccine-type non-bacteremic pneumococcal CAP, and 75\% (95.2\% CI: 41.490.8; $\mathrm{p}<0.001)$ efficacy against vaccine type IPD among adults aged $\geq 65$ years $^{101}$. Due to the CAPITA results, no new recommendations have been issued in either the US or Europe.

\section{ADVISORY COMMITTEE FOR IMMUNIZATION PRACTICES RECOMMENDATIONS 2015 FOR PCV13 AND PPV23 IN ADULTS ${ }^{102}$}

- Pneumococcal vaccine in naïve persons $\geq 65$ years: naïve persons should receive a single dose of PCV13 first, followed by a dose of PPV23 $\geq$ one year later.

- Prior vaccination with PPV23 at age $\geq 65$ years: adults aged $\geq 65$ years who have previously received $\geq 1$ doses of PPV23 should also receive a dose of PCV13 if they have not yet received it. A dose of PCV13 should be given $\geq 1$ year after receipt of the most recent PPV23 dose. In the case of patients who need repeating PPV23, the period between received PCV13 and the new dose of PPV23 should be $\geq 1$ year, and five years after the most recent dose of PPV23.

- ACIP recommendations for immunocompromised patients remain unchanged ${ }^{103}$.

- The recommendations for routine PCV13 use among adults aged $\geq 65$ years will be re-evaluated in 2018 and revised as needed.

\section{ADVISORY COMMITTEE FOR IMMUNIZATION PRACTICES RECOMMENDATIONS FOR PCV13 AND PPV23 IN PATIENTS AGED 19-64 YEARS WITH IMMUNOCOMPROMISED CONDITIONS OR ANATOMICAL OR FUNCTIONAL ASPLENIA, CEREBROSPINAL FLUID LEAKS OR COCHLEAR IMPLANTS}

- Pneumococcal vaccine-naïve: initial dose of PCV13 followed by one dose of PPV23 ( $\geq 8$ weeks following dose of PCV13). A second dose of PPV23 is recommended five years after the first PPV23 dose for persons aged 19-64 with immunocompromised conditions or with anatomical or functional asplenia.

- Previously vaccinated with PPV23: one dose of PCV13 ( $\geq 1$ year after receipt of most recent PPSV23 dose) followed by one dose of PPV23 ( $\geq 8$ weeks following dose of PCV13, and $\geq 5$ years since most recent dose of PPV23).

\section{EUROPEAN CONSIDERATION FOR PCV13 VACCINATION}

In March 2015, the European Commission approved and issued indications for PCV13 
(PCV13 Summary of Product Characteristics, July 2015):

- PCV13 is indicated for active immunization for the prevention of IPD, pneumonia, and acute otitis media in infants, children, and adolescents from 6 weeks to 17 years of age;

- It is also indicated for active immunization for the prevention of IPD and pneumonia in adults $\geq 18$ years of age, and the elderly.

\section{ON-GOING STUDIES OF NEW TREATMENTS IN COMMUNITY- ACQUIRED PNEUMONIA}

Several new antibiotics are in clinical development, with promising results for treating CAP.

\section{Ceftaroline fosamil}

Ceftaroline fosamil is a fifth-generation, parenteral, extended-spectrum cephalosporin that binds to penicillin-binding proteins and prevents synthesis of the bacterial cell wall. Antimicrobial activity is against gram-positive organisms, including S. pneumoniae, Streptococcus pyogenes, S. aureus (including MRSA, vancomycin-resistant $S$. aureus [VRSA], and hetero-resistant vancomycin intermediate $S$. aureus [hVISA]), as well as many common gram-negative organisms, such as Haemophilus influenzae and Moraxella catarrhalis ${ }^{104}$.

\section{Ceftobiprole}

Ceftobiprole is a broad-spectrum parenteral cephalosporin and has microbiological activity against most typical bacterial pathogens that cause CAP, including MRSA ${ }^{105}$.

\section{Nemonoxacin}

Nemonoxacin is a non-fluorinated, broad-spectrum quinolone. Nemonoxacin displayed greater activity than the fluoroquinolones (levofloxacin) against methicillin-sensitive $S$. aureus, methicillin-sensitive Staphylococcus epidermidis (MSSE), methicillin-resistant S. epidermidis (MRSE), S. pneumoniae, and Enterobacter faecalis. Interestingly, nemonoxacin maintained better activity against community-acquired MRSA than against hospital-acquired MRSA ${ }^{106}$

\section{Solithromycin}

Solithromycin is a novel fluoroketolide with high potency against gram-positive and gramnegative bacteria commonly associated with CAP and skin structure infections ${ }^{107}$.

\section{Cethromycin}

Cethromycin is a new fluoroketolide with a reported high potency against gram-positive and gram-negative bacteria, and atypical pathogens (including mycoplasma and ureaplasma). It also has in vitro activity against penicillin-resistant and macrolide-resistant grampositive organisms, possibly due to a high affinity for the target site on the ribosomal unit ${ }^{108}$.

\section{CONCLUSIONS}

Community-acquired pneumonia remains a significant cause of morbidity and mortality 
worldwide despite the improved management of CAP patients. In the past 15 years, several population-based data studies on the epidemiology and microbial aetiology of CAP have been published, showing that S. pneumoniae (pneumococcus) is still the most frequent pathogen in CAP in all settings, in all age groups, and regardless of comorbidity. Respiratory viruses, especially influenza virus A and $\mathrm{B}$, respiratory syncytial virus, and rhinovirus, are major causes of CAP. Despite the development of new molecular techniques and the implementation of diagnostic tests in CAP, more than $50 \%$ of cases remain without microbiological diagnosis. A major problem is the increased rate of antibiotic resistance of frequent pathogens in CAP and the emergence of MDR pathogens.

\section{REFERENCES}

1. Welte T, Torres A, Nathwani D. Clinical and economic burden of community-acquired pneumonia among adults in Europe. Thorax. 2012;67:71-9.

2. Trotter CL, Stuart JM, George R, Miller E. Increasing hospital admissions for pneumonia, England. Emerg Infect Dis. 2008;14:727-33.

3. Simonetti AF, Garcia-Vidal C, Viasus D et al. Declining mortality among hospitalized patients with community-acquired pneumonia. Clin Microbiol Infect. 2016;22:567.

4. Blasi F, Mantero M, Santus P, Tarsia P. Understanding the burden of pneumococcal disease in adults. Clin Microbiol Infect. 2012;18(Suppl 5):7-14.

5. Cilloniz C, Polverino E, Ewig S et al. Impact of age and comorbidity on cause and outcome in community-acquired pneumonia. Chest. 2013;144: 999-1007.

6. Jain S, Self WH, Wunderink RG et al. Community-Acquired Pneumonia Requiring Hospitalization among U.S. Adults. N Engl J Med. 2015;373: 415-27.

7. Dawood FS, Jain S, Finelli L et al. Emergence of a novel swine-origin influenza A (H1N1) virus in humans. N Engl J Med. 2009;360:2605-15.

8. Van Boeckel TP, Gandra S, Ashok A et al. Global antibiotic consumption 2000 to 2010: an analysis of national pharmaceutical sales data. Lancet Infect Dis. 2014;14:742-50

9. World Health Organization (WHO). The top 10 causes of death. 2016.

10. Murphy SL, Xu JQ, Kochanek KD. Deaths: Preliminary data for 2010. Nat Vital Statist Reports. 2012;60.

11. GBD 2013 Mortality and Causes of Death Collaborators. Global, regional, and national age-sex specific all-cause and cause-specific mortality for 240 causes of death, 1990-2013: a systematic analysis for the Global Burden of Disease Study 2013. Lancet. 2015;385:117-71.

12. Torres A, Peetermans WE, Viegi G, Blasi F. Risk factors for community-acquired pneumonia in adults in Europe: a literature review. Thorax. 2013;68: 1057-65.
13. Rozenbaum MH, Mangen MJ, Huijts SM, van der Werf TS, Postma MJ. Incidence, direct costs and duration of hospitalization of patients hospitalized with community acquired pneumonia: A nationwide retrospective claims database analysis. Vaccine. 2015;33:3193-9.

14. Weycker D, Farkouh RA, Strutton DR, Edelsberg J, Shea KM, Pelton SI. Rates and costs of invasive pneumococcal disease and pneumonia in persons with underlying medical conditions. BMC Health Serv Res. 2016;16:182.

15. Almirall J, Bolibar I, Serra-Prat M et al. New evidence of risk factors for community-acquired pneumonia: a population-based study. Eur Respir J. 2008;31:1274-84.

16. Schnoor M, Klante T, Beckmann M et al. Risk factors for community-acquired pneumonia in German adults: the impact of children in the household. Epidemiol Infect. 2007;135:1389-97.

17. Jennings LC, Anderson TP, Beynon KA et al. Incidence and characteristics of viral community-acquired pneumonia in adults. Thorax. 2008;63:42-8.

18. Ramsey CD, Kumar A. Influenza and endemic viral pneumonia. Crit Care Clin. 2013;29:1069-86.

19. Li G, Cook DJ, Thabane L et al. Risk factors for mortality in patients admitted to intensive care units with pneumonia. Respir Res. 2016;17:80.

20. Kohlhammer Y, Schwartz M, Raspe H, Schafer T. [Risk factors for community acquired pneumonia (CAP). A systematic review]. Dtsch Med Wochenschr. 2005;130:381-6.

21. Samokhvalov AV, Irving HM, Rehm J. Alcohol consumption as a risk factor for pneumonia: a systematic review and meta-analysis. Epidemiol Infect. 2010;138:1789-95.

22. Restrepo MI, Mortensen EM, Pugh JA, Anzueto A. COPD is associated with increased mortality in patients with community-acquired pneumonia. Eur Respir J. 2006;28:346-51.

23. Ernst P, Gonzalez AV, Brassard P, Suissa S. Inhaled corticosteroid use in chronic obstructive pulmonary disease and the risk of hospitalization for pneumonia. Am J Respir Crit Care Med. 2007;176:162-6.

24. Joo MJ, Au DH, Fitzgibbon ML, Lee TA. Inhaled corticosteroids and risk of pneumonia in newly diagnosed COPD. Respir Med. 2010;104:246-52.

25. Yamauchi Y, Yasunaga H, Hasegawa W et al. Effect of outpatient therapy with inhaled corticosteroids on decreasing in-hospital mortality from pneumonia in patients with COPD. Int J Chron Obstruct Pulmon Dis. 2016;11:1403-11.

26. Vinogradova Y, Hippisley-Cox J, Coupland C. Identification of new risk factors for pneumonia: population-based case-control study. Br J Gen Pract. 2009;59:e329-38.

27. Kornum JB, Thomsen RW, Riis A, Lervang HH, Schonheyder HC, Sorensen HT. Diabetes, glycemic control, and risk of hospitalization with pneumonia: a population-based case-control study. Diabetes Care. 2008;31:1541-5.

28. Madeddu G, Porqueddu EM, Cambosu F et al. Bacterial community acquired pneumonia in HIV-infected inpatients in the highly active antiretroviral therapy era. Infection. 2008;36:231-6.

29. Cai X, Fu Y, Chen Q. Association between TLR4 A299G polymorphism and pneumonia risk: a meta-analysis. Med Sci Monit. 2015;21:625-9.

30. Misch EA, Verbon A, Prins JM, Skerrett SJ, Hawn TR. A TLR6 polymorphism is associated with increased risk of Legionnaires' disease. Genes Immun. 2013;14:420-6.

31. Hermos JA, Young MM, Fonda JR, Gagnon DR, Fiore LD, Lawler EV. Risk of community-acquired pneumonia in veteran patients to whom proton pump inhibitors were dispensed. Clin Infect Dis. 2012;54:33-42.

32. Lambert AA, Lam JO, Paik JJ, Ugarte-Gil C, Drummond MB, Crowell TA Risk of community-acquired pneumonia with outpatient proton-pump inhibitor therapy: a systematic review and meta-analysis. PLoS One. 2015 10:e0128004

33. Cilloniz C, Ewig S, Polverino E et al. Microbial aetiology of community-acquired pneumonia and its relation to severity. Thorax. 2011;66:340-6.

34. Cilloniz C, Ewig S, Polverino E et al. Community-acquired pneumonia in outpatients: aetiology and outcomes. Eur Respir J. 2012;40:931-8.

35. Centers for Disease Control and Prevention (CDC). Current cigarette smoking among adults - United States, 2011. MMWR Morb Mortal Wkly Rep. 2012;61:889-94. 
36. Rozenbaum MH, Pechlivanoglou P, van der Werf TS, Lo-Ten-Foe JR, Postma MJ, Hak E. The role of Streptococcus pneumoniae in community-acquired pneumonia among adults in Europe: a meta-analysis. Eur J Clin Microbiol Infect Dis. 2013;32:305-16.

37. Arnold FW, Summersgill JT, Lajoie AS et al. A worldwide perspective of atypical pathogens in community-acquired pneumonia. Am J Respir Crit Care Med. 2007;175:1086-93.

38. Karhu J, la-Kokko TI, Vuorinen T, Ohtonen P, Syrjala H. Lower respiratory tract virus findings in mechanically ventilated patients with severe community-acquired pneumonia. Clin Infect Dis. 2014;59:62-70.

39. Garg S, Jain S, Dawood FS et al. Pneumonia among adults hospitalized with laboratory-confirmed seasonal influenza virus infection-United States, 2005-2008. BMC Infect Dis. 2015;15:369.

40. Lee N, Qureshi ST. Other viral pneumonias: coronavirus, respiratory syncytial virus, adenovirus, hantavirus. Crit Care Clin. 2013;29:1045-68.

41. van den Hoogen BG, de Jong JC, Groen J et al. A newly discovered human pneumovirus isolated from young children with respiratory tract disease. Nat Med. 2001;7:719-24.

42. Holmes KV. SARS-associated coronavirus. N Engl J Med. 2003;348:1948-51.

43. Allander T, Tammi MT, Eriksson M, Bjerkner A, Tiveljung-Lindell A, Andersson B. Cloning of a human parvovirus by molecular screening of respiratory tract samples. Proc Natl Acad Sci USA. 2005;102:12891-6.

44. Cauchemez S, Fraser C, Van K et al. Middle East respiratory syndrome coronavirus: quantification of the extent of the epidemic, surveillance biases, and transmissibility. Lancet Infect Dis. 2014;14:50-6.

45. Bradley SF. Staphylococcus aureus pneumonia: emergence of MRSA in the community. Semin Respir Crit Care Med. 2005;26:643-9.

46. Prina E, Ranzani OT, Polverino E et al. Risk factors associated with potentially antibiotic-resistant pathogens in community-acquired pneumonia. Ann Am Thorac Soc. 2015;12:153-60.

47. Aliberti S, Cilloniz C, Chalmers JD et al. Multidrug-resistant pathogens in hospitalised patients coming from the community with pneumonia: a European perspective. Thorax. 2013;68:997-9.

48. Lynch JP, III, Zhanel GG. Streptococcus pneumoniae: does antimicrobial resistance matter? Semin Respir Crit Care Med. 2009;30:210-38.

49. Stephens DS, Zughaier SM, Whitney CG et al. Incidence of macrolide resistance in Streptococcus pneumoniae after introduction of the pneumococcal conjugate vaccine: population-based assessment. Lancet. 2005;365: 855-63.

50. Cilloniz C, Albert RK, Liapikou A et al. The effect of macrolide-resistance on the presentation and outcome of patients hospitalized for Streptococcus pneumoniae pneumonia. Am J Respir Crit Care Med. 2015;191:1265-72.

51. Otto M. Basis of virulence in community-associated methicillin-resistant Staphylococcus aureus. Annu Rev Microbiol. 2010;64:143-62.

52. Yoshimoto A, Nakamura H, Fujimura M, Nakao S. Severe community-acquired pneumonia in an intensive care unit: risk factors for mortality. Intern Med. 2005;44:710-6

53. Cilloniz C, Gabarrus A, Ferrer M et al. Community-acquired pneumonia due to multidrug and non-multidrug resistant Pseudomonas aeruginosa. Chest. 2016;150:415-25.

54. Hanada S, Morozumi M, Takahashi Y et al. Community-acquired pneumonia caused by macrolide-resistant Mycoplasma pneumoniae in adults. Intern Med. 2014;53:1675-8.

55. Zhou Z, Li X, Chen X et al. Macrolide-resistant Mycoplasma pneumoniae in adults in Zhejiang, China. Antimicrob Agents Chemother. 2015;59:104851.

56. Dumke R, Schnee C, Pletz MW et al. Mycoplasma pneumoniae and Chlamydia spp. infection in community-acquired pneumonia, Germany, 20112012. Emerg Infect Dis. 2015;21:426-34.

57. Yamada M, Buller R, Bledsoe S, Storch GA. Rising rates of macrolide-resistant Mycoplasma pneumoniae in the central United States. Pediatr Infect Dis J. 2012;31:409-0.

58. Kang CI, Song JH, Kim SH et al. Risk factors for levofloxacin-nonsusceptible Streptococcus pneumoniae in community-acquired pneumococcal pneumonia: a nested case-control study. Eur J Clin Microbiol Infect Dis 2014;33:55-9.

59. Jones RN, Sader HS, Mendes RE, Flamm RK. Update on antimicrobial susceptibility trends among Streptococcus pneumoniae in the United States: report of ceftaroline activity from the SENTRY Antimicrobial Surveillance Program (1998-2011). Diagn Microbiol Infect Dis. 2013;75:107-9.

60. European Centre for Disease Prevention and Control (ECDC). Antimicrobial resistance surveillance in Europe 2012. 2012.

61. Kim SH, Song JH, Chung DR et al. Changing trends in antimicrobial resistance and serotypes of Streptococcus pneumoniae isolates in Asian countries: an Asian Network for Surveillance of Resistant Pathogens (ANSORP) study. Antimicrob Agents Chemother. 2012;56:1418-26.

62. Wooten DA, Winston LG. Risk factors for methicillin-resistant Staphylococcus aureus in patients with community-onset and hospital-onset pneumonia. Respir Med. 2013;107:1266-70.

63. David MZ, Daum RS. Community-associated methicillin-resistant Staphylococcus aureus: epidemiology and clinical consequences of an emerging epidemic. Clin Microbiol Rev. 2010;23:616-87.

64. Knox J, Uhlemann AC, Lowy FD. Staphylococcus aureus infections: transmission within households and the community. Trends Microbiol. 2015;23: 437-44.

65. Garau J, Baquero F, Perez-Trallero E et al. Factors impacting on length of stay and mortality of community-acquired pneumonia. Clin Microbiol Infect. 2008;14:322-9.

66. Mandell LA, Wunderink RG, Anzueto A et al. Infectious Diseases Society of America/American Thoracic Society consensus guidelines on the management of community-acquired pneumonia in adults. Clin Infect Dis. 2007;44(Suppl 2):S27-72.

67. Lim WS, Baudouin SV, George RC et al. BTS guidelines for the management of community acquired pneumonia in adults: update 2009. Thorax. 2009; 64(Suppl 3):iii1-55.

68. Resti M, Micheli A, Moriondo M et al. Comparison of the effect of antibiotic treatment on the possibility of diagnosing invasive pneumococcal disease by culture or molecular methods: a prospective, observational study of children and adolescents with proven pneumococcal infection. Clin Ther 2009;31:1266-73.

69. Johansson N, Kalin M, Giske CG, Hedlund J. Quantitative detection of Streptococcus pneumoniae from sputum samples with real-time quantitative polymerase chain reaction for etiologic diagnosis of community-acquired pneumonia. Diagn Microbiol Infect Dis. 2008;60:255-61.

70. Gadsby NJ, Russell CD, McHugh MP et al. Comprehensive molecular testing for respiratory pathogens in community-acquired pneumonia. Clin Infect Dis. 2016;62:817-23.

71. Menendez R, Martinez R, Reyes S et al. Biomarkers improve mortality prediction by prognostic scales in community-acquired pneumonia. Thorax. 2009;64:587-91.

72. Muller F, Christ-Crain M, Bregenzer T et al. Procalcitonin levels predict bacteremia in patients with community-acquired pneumonia: a prospective cohort trial. Chest. 2010;138:121-9.

73. Johansson N, Kalin M, Backman-Johansson C, Larsson A, Nilsson K, Hedlund J. Procalcitonin levels in community-acquired pneumonia - correlation with aetiology and severity. Scand J Infect Dis. 2014;46:787-91.

74. Menendez R, Sahuquillo-Arce JM, Reyes S et al. Cytokine activation patterns and biomarkers are influenced by microorganisms in community-acquired pneumonia. Chest. 2012;141:1537-45.

75. de JE, van Oers JA, Beishuizen A et al. Efficacy and safety of procalcitonin guidance in reducing the duration of antibiotic treatment in critically ill patients: a randomised, controlled, open-label trial. Lancet Infect Dis. 2016 16:819-27.

76. Chalmers JD, Singanayagam A, Hill AT. C-reactive protein is an independent predictor of severity in community-acquired pneumonia. Am J Med. 2008;121:219-25.

77. Hohenthal U, Sipila J, Vainionpaa R et al. Diagnostic value of bronchoalveolar lavage in community-acquired pneumonia in a routine setting: a 
study on patients treated in a Finnish university hospital. Scand J Infect Dis. 2004;36:198-203.

78. Espana PP, Capelastegui A, Bilbao A et al. Utility of two biomarkers for directing care among patients with non-severe community-acquired pneumonia. Eur J Clin Microbiol Infect Dis. 2012;31:3397-405.

79. Christ-Crain M, Morgenthaler NG, Stolz D et al. Pro-adrenomedullin to predict severity and outcome in community-acquired pneumonia [ISRCTN04176397]. Crit Care. 2006;10:R96.

80. Shilon Y, Shitrit AB, Rudensky B et al. A rapid quantitative D-dimer assay at admission correlates with the severity of community acquired pneumonia. Blood Coagul Fibrinolysis. 2003;14:745-8.

81. Fine MJ, Auble TE, Yealy DM et al. A prediction rule to identify low-risk patients with community-acquired pneumonia. N Engl J Med. 1997;336: 243-50

82. Lim WS, van der Eerden MM, Laing R et al. Defining community acquired pneumonia severity on presentation to hospital: an international derivation and validation study. Thorax. 2003;58:377-82.

83. Chalmers JD, Singanayagam A, Akram AR et al. Severity assessment tools for predicting mortality in hospitalised patients with community-acquired pneumonia. Systematic review and meta-analysis. Thorax. 2010;65:878-83.

84. Talwar A, Lee H, Fein A. Community-acquired pneumonia: what is relevant and what is not? Curr Opin Pulm Med. 2007;13:177-85.

85. Liu JL, Xu F, Hui Z et al. Expanded CURB-65: a new score system predicts severity of community-acquired pneumonia with superior efficiency. Sci Rep. 2016;6:22911.

86. Waterer GW, Kessler LA, Wunderink RG. Medium-term survival after hospitalization with community-acquired pneumonia. Am J Respir Crit Care Med. 2004;169:910-4.

87. Holter JC, Ueland T, Jenum PA et al. Risk factors for long-term mortality after hospitalization for community-acquired pneumonia: A 5-year prospective follow-up study. PLoS One. 2016;11:e0148741.

88. Bordon J, Wiemken T, Peyrani P et al. Decrease in long-term survival for hospitalized patients with community-acquired pneumonia. Chest. 2010; 138:279-83.

89. Aliberti S, Ramirez JA. Cardiac diseases complicating community-acquired pneumonia. Curr Opin Infect Dis. 2014;27:295-301.

90. Houck PM, Bratzler DW, Nsa W, Ma A, Bartlett JG. Timing of antibiotic administration and outcomes for Medicare patients hospitalized with community-acquired pneumonia. Arch Intern Med. 2004;164:637-44.

91. Menendez R, Torres A, Zalacain R et al. Risk factors of treatment failure in community acquired pneumonia: implications for disease outcome. Thorax. 2004;59:960-5.

92. Rodrigo C, Leonardi-Bee J, Nguyen-Van-Tam JS, Lim WS. Effect of corticosteroid therapy on influenza-related mortality: a systematic review and meta-analysis. J Infect Dis. 2015;212:183-94.

93. Chalmers JD, Singanayagam A, Murray MP, Hill AT. Prior statin use is associated with improved outcomes in community-acquired pneumonia. Am J Med. 2008;121:1002-7.

94. Anderson R, Steel HC, Cockeran R et al. Clarithromycin alone and in combination with ceftriaxone inhibits the production of pneumolysin by both macrolide-susceptible and macrolide-resistant strains of Streptococcus pneumoniae. J Antimicrob Chemother. 2007;59:224-9.
95. Feldman C, Anderson R. Recent advances in our understanding of Streptococcus pneumoniae infection. F1000Prime Rep. 2014;6:82.

96. Ochoa-Gondar O, Vila-Corcoles A, Rodriguez-Blanco T et al. Effectiveness of the 23-valent pneumococcal polysaccharide vaccine against communityacquired pneumonia in the general population aged $>/=60$ years: 3 years of follow-up in the CAPAMIS study. Clin Infect Dis. 2014;58:909-17.

97. Leventer-Roberts M, Feldman BS, Brufman I, Cohen-Stavi CJ, Hoshen M, Balicer RD. Effectiveness of 23-valent pneumococcal polysaccharide vaccine against invasive disease and hospital-treated pneumonia among people aged $>/=65$ years: a retrospective case-control study. Clin Infect Dis 2015;60:1472-80.

98. Andrews NJ, Waight PA, George RC, Slack MP, Miller E. Impact and effectiveness of 23-valent pneumococcal polysaccharide vaccine against invasive pneumococcal disease in the elderly in England and Wales. Vaccine. 2012;30:6802-8.

99. Moore MR, Whitney CG. Use of pneumococcal disease epidemiology to set policy and prevent disease during 20 years of the Emerging Infections Program. Emerg Infect Dis. 2015;21:1551-6.

100. Food and Drug Administration, Department Of Health And Human Services. Supplement approval. 2016.

101. Bonten MJ, Huijts SM, Bolkenbaas M et al. Polysaccharide conjugate vaccine against pneumococcal pneumonia in adults. N Engl J Med. 2015;372: 1114-25.

102. Kobayashi M, Bennett NM, Gierke R et al. Intervals between PCV13 and PPSV23 vaccines: Recommendations of the Advisory Committee on Immunization Practices (ACIP). MMWR Morb Mortal Wkly Rep. 2015;64:944-7.

103. Centers for Disease Control and Prevention (CDC). Use of 13-valent pneumococcal conjugate vaccine and 23-valent pneumococcal polysaccharide vaccine for adults with immunocompromising conditions: recommendations of the Advisory Committee on Immunization Practices (ACIP). MMWR Morb Mortal Wkly Rep. 2012;61:816-9.

104. Low DE, File TM, Jr., Eckburg PB et al. FOCUS 2: a randomized, double-blinded, multicentre, Phase III trial of the efficacy and safety of ceftaroline fosamil versus ceftriaxone in community-acquired pneumonia. J Antimicrob Chemother. 2011;66(Suppl 3):iii33-44.

105. Awad SS, Rodriguez AH, Chuang YC et al. A phase 3 randomized double-blind comparison of ceftobiprole medocaril versus ceftazidime plus linezolid for the treatment of hospital-acquired pneumonia. Clin Infect Dis 2014; 59:51-61

106. Lauderdale TL, Shiau YR, Lai JF, Chen HC, King CH. Comparative in vitro activities of nemonoxacin (TG-873870), a novel nonfluorinated quinolone, and other quinolones against clinical isolates. Antimicrob Agents Chemother. 2010;54:1338-42.

107. Oldach D, Clark K, Schranz J et al. Randomized, double-blind, multicenter phase 2 study comparing the efficacy and safety of oral solithromycin (CEM-101) to those of oral levofloxacin in the treatment of patients with community-acquired bacterial pneumonia. Antimicrob Agents Chemother 2013;57:2526-34.

108. Putnam SD, Castanheira M, Moet GJ, Farrell DJ, Jones RN. CEM-101, novel fluoroketolide: antimicrobial activity against a diverse collection of Gram-positive and Gram-negative bacteria. Diagn Microbiol Infect Dis. 2010;66:393-401. 